\title{
Synergistic Inhibition of Human Carcinoma Cell Growth via Co-Delivery of p53 Plasmid DNA and bcl-2 Antisense Oligodeoxyribonucleotide by Cholic Acid-modified Polyethylenimine
}

\author{
WANLOP WEECHARANGSAN ${ }^{1}$, PRANEET OPANASOPIT ${ }^{2}$, NATTISA NIYOMTHAM ${ }^{3}$, \\ BOON-EK YINGYONGNARONGKUL ${ }^{3}$, PRARTANA KEWSUWAN ${ }^{4}$ and ROBERT J. LEE ${ }^{5}$ \\ ${ }^{1}$ Department of Pharmaceutical Technology, Faculty of Pharmacy, \\ Srinakharinwirot University, Nakhonnayok, Thailand; \\ ${ }^{2}$ Pharmaceutical Development of Green Innovations Group (PDGIG), \\ Faculty of Pharmacy, Silpakorn University, Nakhonpathom, Thailand; \\ ${ }^{3}$ Department of Chemistry and Center of Excellence for Innovation in Chemistry, \\ Faculty of Science, Ramkhamhaeng University, Bangkok, Thailand; \\ ${ }^{4}$ Thailand Institute of Nuclear Technology, Nakhonnayok, Thailand; \\ ${ }^{5}$ Division of Pharmaceutics and Pharmaceutical Chemistry, \\ College of Pharmacy, The Ohio State University, Columbus, OH, U.S.A.
}

\begin{abstract}
Background/Aim: This study investigated the codelivery of plasmid DNA and antisense oligodeoxyribonucleotide (AS ODN) into carcinoma cells by cholic acidmodified polyethylenimine (PEI-CA). Materials and Methods: PEI-CA/plasmid DNA and AS ODN complexes were formulated and evaluated for delivery of plasmid DNA and AS ODN in HeLa cells. The efficiency of co-delivery of plasmid DNA and AS ODN was evaluated by cell growth inhibition using p53 and bcl-2 AS ODN. Results: AS ODN intracellular delivery and green fluorescent protein expression upon cellular transfection were greater than in cells treated with uncomplexed nucleic acids. Treatment of the cells with PEI-CA/p53 plasmid DNA and bcl-2 AS ODN complexes resulted in cell growth inhibition that was greater than that of either PEI-CA/p53 plasmid DNA complexes or PEI-CA/bcl-2 AS ODN complexes alone. Conclusion: The co-delivery of p53 plasmid DNA and bcl-2 AS ODN in PEI-CA complexes enhanced therapeutic activities of both p53 plasmid DNA and bcl-2 AS ODN.
\end{abstract}

Correspondence to: Wanlop Weecharangsan, Ph. D., Department of Pharmaceutical Technology, Faculty of Pharmacy, Srinakharinwirot University, Nakhonnayok, Thailand. Tel: +66 37395094, Fax: +6637 395096, e-mail:wanlop@g.swu.ac.th

Key Words: p53 plasmid DNA, bcl-2 antisense oligodeoxyribonucleotide, co-delivery, cholic acid, polyethylenimine, growth inhibition.
Non-viral systems are desirable as nucleic acid carriers since they are safer than viral systems (1). Among non-viral carriers, a cationic polymer, PEI, has been extensively used in nucleic acid delivery (2). However, its cytotoxicity limited its use (3). Modified PEIs with a hydrophobic moiety have been developed to increase transfection efficiency and decrease cytotoxicity including conjugates of PEIs with deoxycholic acid and cholic acid $(4,5)$.

Co-delivery of different classes of therapeutic nucleic acids has been shown to enhance their therapeutic activity. Co-delivery of SOX9 plasmid DNA and Cbfa-1 siRNA increased the expression of genes related with chondrogenesis by human mesenchymal stem cells transplanted in mice (6). Co-delivery of p53 plasmid DNA and bcl-2 AS ODN synergized in promoting growth inhibition of human carcinoma cells (7).

In our previous published study, co-delivery of plasmid DNA and AS ODN by cationic liposomes was investigated in HeLa cells in separate formulations (7). In this study, we investigated the co-delivery of plasmid DNA and AS ODN by PEI-CA in a single formulation. PEI-CA was evaluated for its ability to form complexes with both plasmid DNA and AS ODN. Particle size and zeta potential of PEI-CA/plasmid DNA and AS ODN complexes were evaluated. The co-delivery of plasmid DNA and AS ODN by PEI-CA was evaluated in HeLa cells. The potential use of the co-delivery with PEI-CA was evaluated using therapeutic nucleic acids, p53 plasmid and bcl2 AS ODN, in terms of cell growth inhibition. 


\section{Materials and Methods}

Materials. PEI-CA (PEI: CA; 1: 0.5 molar ratio) was provided by Dr. Boon-ek Yingyongnarongkul, Department of Chemistry and Center of Excellence for Innovation in Chemistry, Faculty of Science, Ramkhamhaeng University, Bangkok, Thailand. Polyethylenimine (PEI 25KDa, branched), cholic acid (CA), N,N-dicyclohexylcarbodiimide (DCC), 4-dimethylamiopyridine (DMAP), $\mathrm{N}, \mathrm{N}$ dimetylformamide (DMF) and deuterated water $\left(\mathrm{D}_{2} \mathrm{O}\right)$ were purchased from Sigma-Aldrich (St. Louis, MO, USA). Sephadex ${ }^{\mathrm{TM}}$ LH-20 (GE Healthcare Bio-Sciences AB, Uppsala, Sweden). pEGFP-C2 plasmid DNA encoding green fluorescent protein (GFP) was obtained from Clontech (Palo Alto, CA, USA). Plasmid GFP-p53 encoding p53 protein was a gift from Dr. Tyler Jacks (Addgene plasmid \# 12091) (8). AS ODN, a fully phosphorothioated 18-mer oliogonucleotide (sequence: 5'- TACCGTCTGCGACGCCCT-3'), bcl-2 AS ODN, fully phosphorothioated 18-mer oliogonucleotide (Sequence: 5'TCTCCCAGCGTGCGCCAT-3') and Cy3-labeled bcl-2 AS ODN (Sequence: 5'-Cy3-TCTCCCAGCGTGCGCCAT-3') were purchased from Alpha DNA (Quebec, Canada). Six- and 96-well plates were purchased from SPL Life Sciences. (Gyeonggi-do, Republic of Korea). MEM media and fetal bovine serum (FBS) were purchased from Invitrogen (Grand Island, NY, USA). 3-(4,5-Dimethylthiazol-2-yl)-2,5diphenyl tetrazolium bromide (MTT) was purchased from Bio Basic Inc. (Ontario, Canada). HeLa human cervical carcinoma cells were obtained from American Type Culture Collection (ATCC, Rockville, MD, USA).

Plasmid DNA preparation. pEGFP-C2 and GFP-p53 plasmid DNA were used in this study. The plasmid DNAs were purified from DH5$\alpha$ E. coli using the Plasmid Maxi Kit (Geneaid, Taipei City, Taiwan). The purity and concentrations of plasmid DNAs were determined using a cuvette spectrophotometer (Eppendorf Biophotometer plus, Eppendorf AG, Hamburg, Germany). The purity of plasmid DNA was confirmed by gel electrophoresis (1.2\% agarose gel).

Preparation of PEI-CA/nucleic acid complexes. PEI-CA was dissolved in ultrapure sterile water and diluted to the concentrations of 0.1 and $0.5 \mathrm{mg} / \mathrm{ml}$. PEI-CA/nucleic acid complexes were prepared by mixing the plasmid DNA and AS ODN solution with the PEI-CA solution. The mixture was gently pipetted and vortexed for 3-5 sec to initiate complex formation, and allowed to stand for $20 \mathrm{~min}$ at room temperature before use. The concentrations of plasmid DNA and AS ODN used were 4 and $5 \mu \mathrm{g} / \mathrm{ml}$, respectively.

Agarose gel electrophoresis. PEI-CA/nucleic acid complexes were prepared in ultrapure water at varying polymer-to-nucleic acid ratios of $0.0625,0.125,0.25,0.5,1$, and 2 . Ten $\mu \mathrm{l}$ of the complexes containing $0.25 \mu \mathrm{g}$ of pEGFP plasmid DNA and $0.3125 \mu \mathrm{g}$ of AS ODN was mixed with $2 \mu \mathrm{l}$ of gel loading dye. Plasmid DNA, AS ODN, and the complexes were run on $1.2 \%$ agarose gel stained with SYBR green $(0.75 \%)$ in $1 \times \mathrm{TBE}$ buffer and visualized in fluorescence mode using an image analyzer (ImageQuant ${ }^{\mathrm{TM}}$ LAS 4000 mini, GE Healthcare Bioscience AB, Uppsala, Sweden). Electrophoresis was carried out at $100 \mathrm{~V}$ for $15 \mathrm{~min}$.

Size and zeta potential measurements. The particle size and surface charge of PEI-CA/pEGFP plasmid DNA and AS ODN complexes were determined using a Zetasizer Nano ZS (Malvern Instruments
Ltd., Worcestershire, UK). The complexes were prepared in ultrapure sterile water. The measurements were performed using the aqueous flow cell in the automatic mode at $25^{\circ} \mathrm{C}$.

Cell culture. HeLa cells were cultivated in MEM supplemented with $10 \%$ FBS, $100 \mu \mathrm{g} / \mathrm{ml}$ streptomycin, $100 \mathrm{U} / \mathrm{ml}$ penicillin and $1 \%$ amphotericin $\mathrm{B}$, and maintained in a humidified incubator with $5 \%$ $\mathrm{CO}_{2}$ at $37^{\circ} \mathrm{C}$.

AS ODN uptake. HeLa cells were plated at a density of $2.5 \times 10^{5}$ cells/well in 6-well plates, and $20 \mathrm{~h}$ later cells were treated with PEI-CA/pEGFP and Cy3-labeled AS ODN for $4 \mathrm{~h}$ at $37^{\circ} \mathrm{C}$ in a humidified incubator with $5 \% \mathrm{CO}_{2}$. Cells treated with uncomplexed nucleic acids were used as control. The FACS analysis were performed by flow cytometry on a FACSCalibur flow cytometer (BD Biosciences, San Jose, CA, USA) equipped with a fluorescence detector for detecting $\mathrm{Cy} 3$.

GFP expression. Cells were seeded into 6-well plates at a density of $2.5 \times 10^{5}$ cells $/ \mathrm{cm}^{2}$ in $1.5 \mathrm{ml}$ of growth medium for $20 \mathrm{~h}$. The cells were incubated with PEI-CA/pEGFP plasmid DNA and AS ODN complexes for $4 \mathrm{~h}$ at $37^{\circ} \mathrm{C}$ in a humidified incubator with $5 \% \mathrm{CO}_{2}$. After $20 \mathrm{~h}$ incubation, the transfected cells were harvested and scored for GFP-positive cells by flow cytometry (FACSCalibur, BD Biosciences, San Jose, CA, USA) equipped with a fluorescence detector for detecting GFP.

Growth inhibition. HeLa cells were plated at a density of $5 \times 10^{3}$ cells/well in 96-well and incubated for $20 \mathrm{~h}$ at $37^{\circ} \mathrm{C}$ under $5 \% \mathrm{CO}_{2}$ atmosphere. Prior to treatment, the medium was removed and the cells were incubated with $62.5 \mu$ of PEI-CA/p53 plasmid DNA and bcl-2 AS ODN complexes or the blank carrier for $4 \mathrm{~h}$ at $37^{\circ} \mathrm{C}$ under $5 \% \mathrm{CO}_{2}$ atmosphere. Untreated cells and cells transfected with free nucleic acids and PEI/nucleic acid complexes were used as controls. After transfection, the medium was removed, and the cells were returned to culture in $100 \mu \mathrm{l}$ of fresh growth medium at $37^{\circ} \mathrm{C}$ under $5 \% \mathrm{CO}_{2}$ atmosphere for an additional $20 \mathrm{~h}$. Evaluation of growth inhibition was performed by MTT assay using a microplate spectrophotometer (Zenyth $200 \mathrm{rt}$; Anthos Labtech Instruments $\mathrm{GmbH}$, Salzburg, Austria).

Colloidal stability. The colloidal stability of PEI-CA/plasmid DNA and AS ODN complexes was evaluated in 10\% BSA solution.

Statistical analysis. Data were presented as the mean \pm standard deviation. Statistical analysis was performed using one-way analysis of variance (ANOVA) followed by an LSD post hoc test. Differences were considered significant at $p<0.05$.

\section{Results}

Characterization of PEI-CA/pEGFP and AS ODN complexes. The formation of complexes between PEI-CA and pEGFP plus AS ODN was assessed through retardation of nucleic acid electrophoretic mobility by agarose gel electrophoresis at polymer-to- nucleic acid (NA) ratios of $0.0625,0.125,0.25,0.5,1$ and 2 . The free plasmid and AS ODN lane showed the DNA and ODN bands, whereas the band density decreased when the amount of PEI-CA 


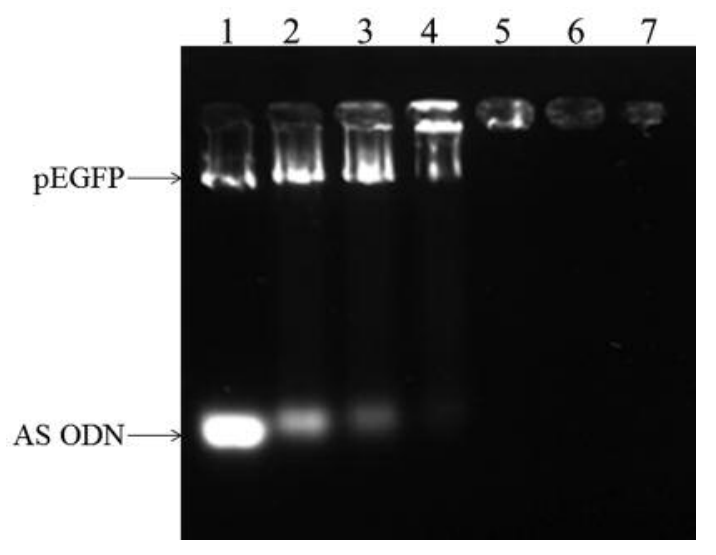

Figure 1. Gel electrophoresis assay of PEI-CA/pEGFP and AS ODN complexes. Lane 1: $0.25 \mu \mathrm{g}$ free $\mathrm{pEGFP}$ and $0.3125 \mu \mathrm{g}$ free $A S O D N$. Lanes 2-8: PEI-CA/pEGFP and AS ODN complexes at polymer-to-NA ratios of $0.0625,0.125,0.25,0.5,1$, and 2 , respectively.

increased. Nucleic acids were completely retarded at polymer-to-NA ratios as low as 0.5 (Figure 1). The particle size and zeta potential of PEI-CA/pEGFP and AS ODN complexes were evaluated at varying polymer-to-NA ratio (Figure 2). The particle size of PEI-CA/pEGFP and AS ODN complexes decreased with increasing polymer-to-NA ratios. The particle size of PEI-CA/pEGFP and AS ODN complexes at polymer-to-NA ratios of 0.2 to 1 was in the range of $87.7 \pm 29.9$ to $182.8 \pm 6.8 \mathrm{~nm}$. The zeta potential of PEI$\mathrm{CA} / \mathrm{pEGFP}$ and AS ODN complexes was negative at a polymer-to-NA ratio of 0.2 , and increased to positive values at a polymer-to-NA ratio above 0.2 .

Transfection efficiency. FACS analysis showed that the Cy3labeled AS ODN-positive cells increased after co-delivery of nucleic acids using PEI-CA (Figure 3). Compared to naked nucleic acids, PEI-CA/pEGFP and Cy3-labeled AS ODN complexes produced a 15.1-fold increase in fluorescence intensity. Transfection efficiency of PEI-CA/pEGFP and AS ODN was evaluated in HeLa cells using pEGFP encoding for green fluorescent protein as a reporter gene. Transfection efficiency of PEI-CA/pEGFP and AS ODN at a polymer-toNA ratio of 0.2 at $24 \mathrm{~h}$ post-transfection. The transfection efficiency of PEI-CA/pEGFP and AS ODN was 14.8-fold higher than that of uncomplexed nucleic acids (Figure 3 ).

Growth inhibition. Growth inhibition of HeLa cells by PEICA/p53 plasmid DNA and bcl-2 AS ODN complexes was evaluated by MTT assay. p53 plasmid DNA and bcl-2 AS ODN co-delivered using PEI-CA exhibited greater growth inhibition than p53 plasmid DNA or bcl-2 AS ODN delivered using PEI-CA alone (Figure 4).

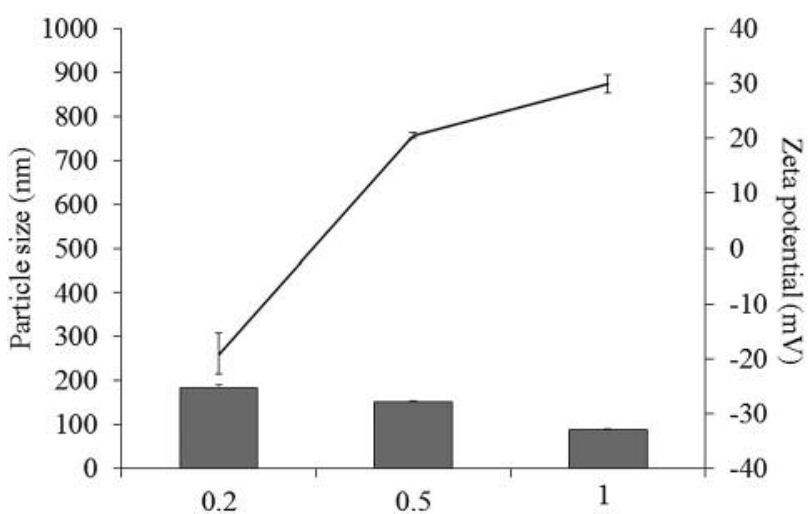

Figure 2. Particle size $(\mathrm{nm})$ and zeta potential $(\mathrm{mV})$ of PEI-CA/pEGFP and $A S O D N$ complexes at varying polymer-to- $N A$ ratios $(0.2,0.5,1)$ in ultrapure water. Each value represents the mean $\pm S . D$. of three measurements.

To determine whether treatment of the cells with PEICA/p53 plasmid DNA and bcl-2 AS ODN complexes inhibits cell growth, the cells were transfected with varying concentrations of p53 plasmid DNA and bcl-2 AS ODN for $4 \mathrm{~h}$ at a polymer-to-NA ratio of 0.5 . Increasing the concentration of p53 plasmid DNA to 1,2 and $4 \mu \mathrm{g} / \mathrm{ml}$, and bcl-2 AS ODN to $1.25,2.5$ and $5 \mu \mathrm{g} / \mathrm{ml}$ in polyplexes increased growth inhibition level on HeLa cells to $10.7 \pm 11.8$, $53.4 \pm 5.7$ and $61.0 \pm 4.6 \%$ that of the control, respectively (Figure 5). Significant growth inhibition was observed from the complexes at p53 plasmid DNA concentrations of 2 and $4 \mu \mathrm{g} / \mathrm{ml}$, and bcl-2 AS ODN concentrations of 2.5 and $5 \mu \mathrm{g} / \mathrm{ml}$ $(p<0.05)$. PEI-CA alone at the concentrations used for complexes of p53 plasmid DNA of 1 and $2 \mu \mathrm{g} / \mathrm{ml}$ and bcl-2 AS ODN of 1.25 and $2.5 \mu \mathrm{g} / \mathrm{ml}$ did not induce significant cytotoxicity compared to with cells treated with p53 plasmid DNA and bcl-2 AS ODN ( $p>0.05)$. However, a high concentration of PEI-CA alone, at a dose equivalent to complexes of p53 plasmid DNA of $4 \mu \mathrm{g} / \mathrm{ml}$ and bcl-2 AS ODN of $5 \mu \mathrm{g} / \mathrm{ml}$ did induce cytotoxicity $(77.5 \pm 16.1 \%$ cell viability) $(p<0.05)$.

PEI-CA/p53 plasmid DNA and bcl-2 AS ODN inhibited cell growth as effectively as PEI/p53 plasmid DNA and bcl-2 AS ODN (Figure 6). However, the cytotoxicity of PEI-CA was less. This indicated that PEI-CA could be an alternative delivery carrier for plasmid DNA and AS ODN.

Colloidal stability. Figure 7 shows the 14 day-colloidal stability of PEI-CA/plasmid DNA and AS ODN complexes. The particle size of PEI-CA/plasmid DNA and AS ODN complexes remained less than $300 \mathrm{~nm}$ during storage at $4^{\circ} \mathrm{C}$ for 14 days. 
A
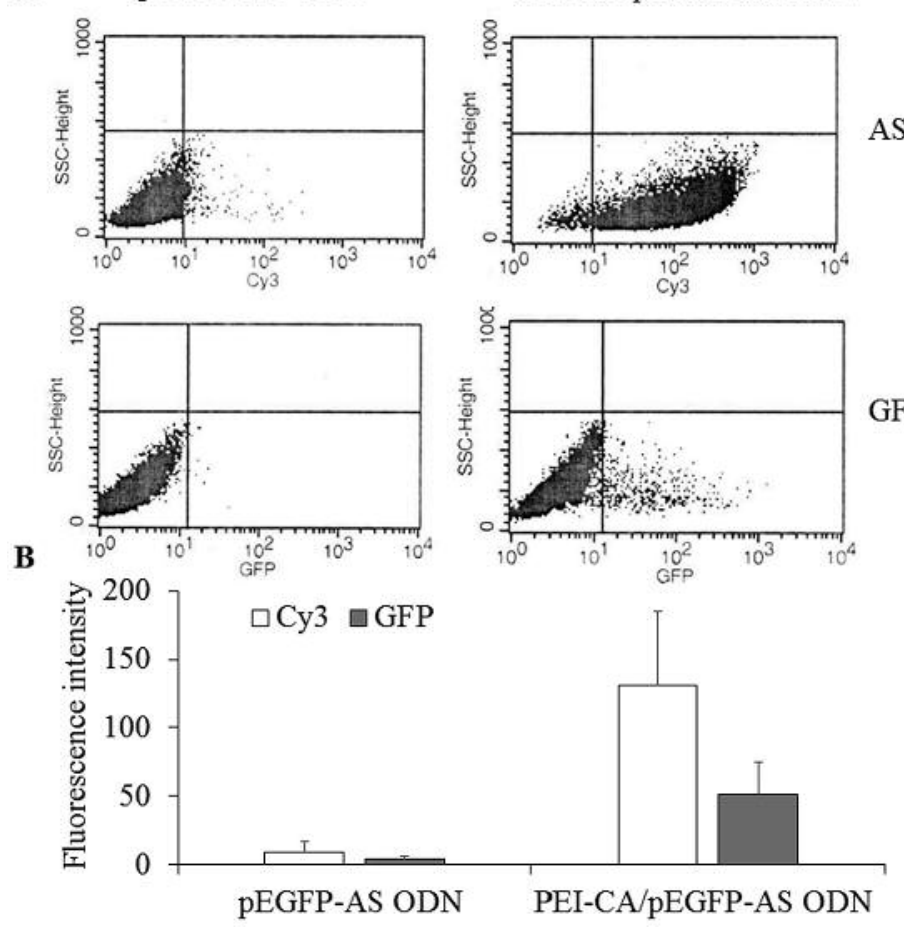

PEI-CA/pEGFP-AS ODN

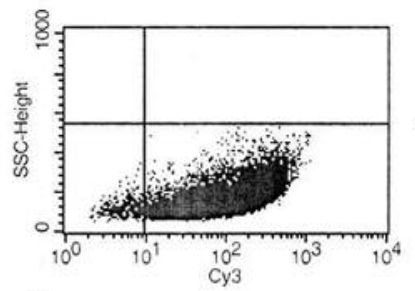

AS ODN uptake

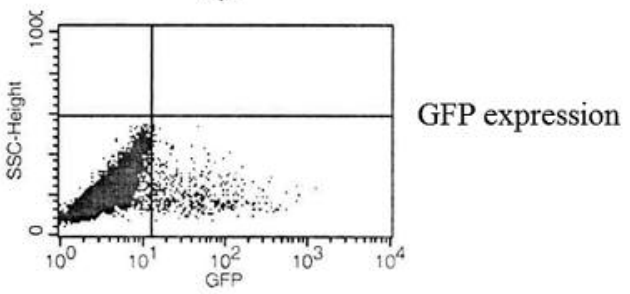

cytometric analysis $(A)$. Fluorescence intensity $(B)$.

\section{Discussion}

The ability to form complexes with the nucleic acid is a required characteristic of a nucleic acid delivery system. The capability of polymer to condense nucleic acid was evaluated by agarose gel electrophoresis, particle size and zeta potential measurements. PEI-CA efficiently condensed plasmid DNA and AS ODN to nanosized complexes. Polymer gene carriers have been reported to efficiently condense plasmid DNA and siRNA into nanosized complexes $(9,10)$

PEI-CA/pEGFP and AS ODN complexes facilitated efficient AS ODN uptake and GFP gene expression. Polyplexes with particle size of less than $200 \mathrm{~nm}$ can readily enter cells (11). PEI/DNA complexes have been demonstrated to enter cells via sulfated proteoglycans (12). Kim et al. showed that deoxycholic acid-modified PEI 1.8KDa had higher siRNA uptake than PEI 25KDa and PEI 1.8KDa (4).

Our study showed that the growth inhibitory activity was more substantial in HeLa cells treated with PEI-CA/p53 plasmid DNA and bcl-2 AS ODN complexes than those treated with PEI-CA/p53 plasmid DNA complexes or PEI$\mathrm{CA} / \mathrm{bcl}-2$ AS ODN complexes alone. This finding was in agreement with our previous report that co-delivery of p53 plasmid DNA and bcl-2 AS ODN by cationic liposomes significantly inhibited cell growth and at a higher rate than either p53 or bcl-2 AS ODN alone (7).

Delivery of p53 plasmid DNA and bcl-2 AS ODN has been reported in cancer growth inhibition. B16-F16 tumor metastases in lung of melanoma lung metastasis mouse model were inhibited by aerosol delivery of PEI/p53 DNA complexes (13). PLGA nanoparticles containing p53 plasmid DNA increased tumor apoptosis, inhibited tumor growth and promoted survival time in MDA-MB-435 carcinoma mouse model (14). Tumor volume in Swiss albino mice was decreased by chitosan nanoparticles loaded with bcl-2 siRNA (15).

Co-delivery strategy of nucleic acid by polymer-based delivery systems has been shown to be a promising approach that improves the biological or therapeutic activity. Chen et al. reported that co-transfection of CCR7 and gp100 plasmid DNA using spermine-dextran exhibited greater tumor inhibition than that with gp100 plasmid DNA alone (16).

The growth inhibition by the co-delivery of p53 plasmid DNA and bcl-2 AS ODN by PEI-CA was influenced by the concentrations of p53 plasmid DNA and bcl-2 AS ODN. The growth inhibition of HeLa cells after co-delivery with PEI-CA increased with increased p53 plasmid DNA concentration from 1 to $4 \mu \mathrm{g} / \mathrm{ml}$, and bcl-2 AS ODN concentration from 1.25 to $5 \mu \mathrm{g} / \mathrm{ml}$. Weecharangsan et al. showed that growth 


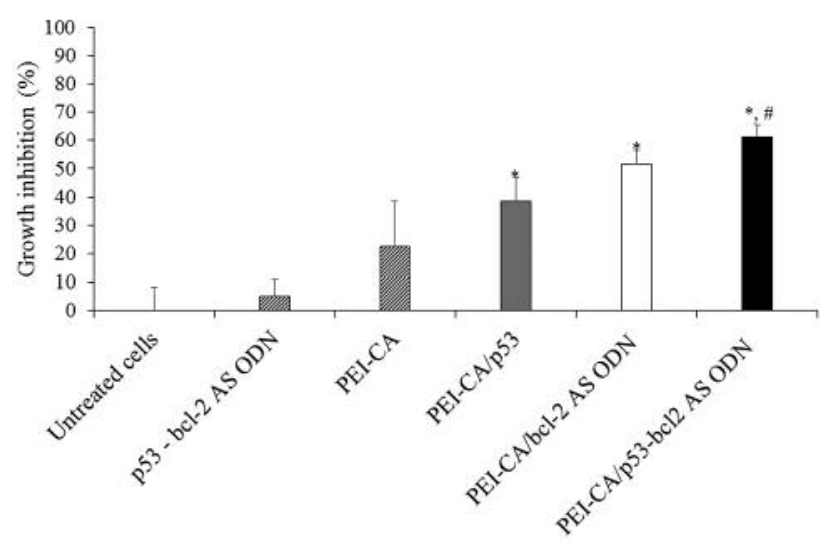

Figure 4. Growth inhibition by PEI-CA/p53 plasmid DNA complexes, PEI-CA/bcl-2 AS ODN complexes, and PEI-CA/p53 plasmid DNA and bcl-2 AS ODN complexes, at a polymer-to-NA ratio of 0.5 in HeLa cells. ${ }^{*} p<0.05$ when compared to cells treated with $p 53$ plasmid DNA and bcl-2 AS ODN, and cells treated with PEI-CA; ${ }^{p}<<0.05$ compared to cells treated with PEI-CA/p53 plasmid DNA. Each value represents the mean \pm S.D. of three wells.

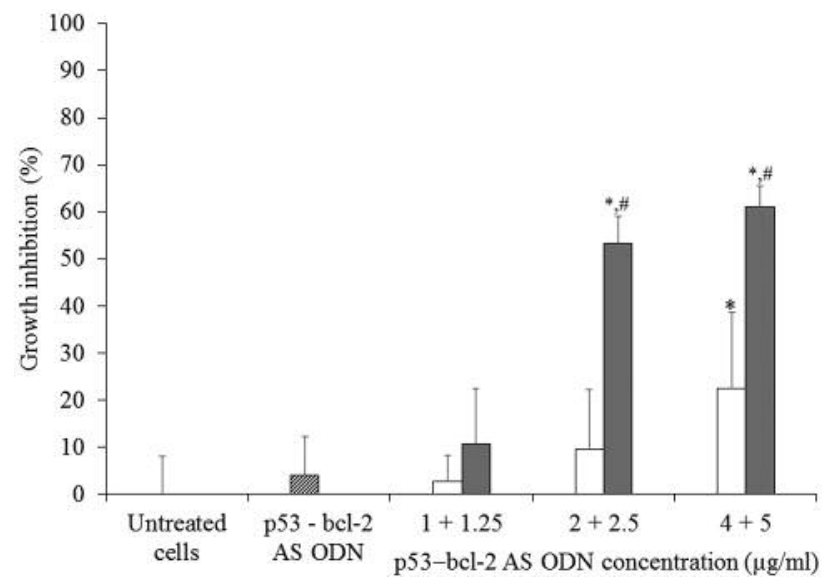

Figure 5. Effect of p53 plasmid DNA and bcl-2 AS ODN concentrations of PEI-CA/p53 plasmid DNA and bcl-2 AS ODN complexes at a polymer-to-NA ratio of 0.5 on HeLa cell growth. Dash bar: $p 53$ plasmid DNA and bcl-2 AS ODN; white bar: PEI-CA; grey bar: PEI-CA/p53 plasmid DNA and bcl-2 AS ODN complexes. ${ }^{*} p<0.05$ compared to untreated cells, and cells treated with p53-bcl-2 AS ODN; ${ }^{p} p<0.05$ compared to cells treated with PEI-CA/p53 plasmid DNA and bcl-2 AS ODN complexes at the p53 plasmid DNA and bcl-2 AS ODN concentrations of 1 and $1.25 \mu \mathrm{g} / \mathrm{ml}$. Each value represents the mean $\pm S . D$. of three wells.

inhibition increased with increasing concentration of bcl-2 AS ODN in KB human oral carcinoma cells transfected with human serum albumin-coated liposome-bcl-2 AS ODN complexes (17).

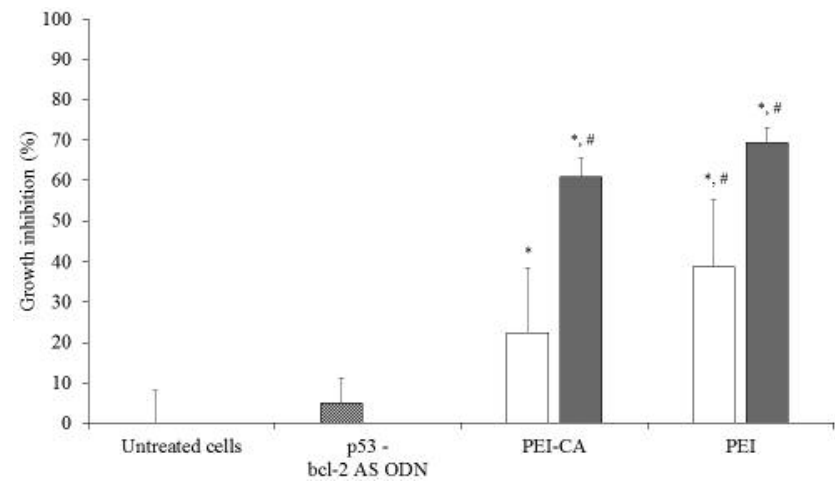

Figure 6. Growth inhibition of HeLa cells by PEI-CA/p53 plasmid DNA and bcl-2 AS ODN complexes and PEI/p53 plasmid DNA and bcl-2 AS ODN complexes at a polymer-to-NA ratio of 0.5 in HeLa cells. White bar: polymer; grey bar: polymer/p53 plasmid DNA and bcl-2 AS ODN complexes. ${ }^{*} p<0.05$ compared with untreated cells; ${ }^{*} p<0.05$ compared with untreated cells, and cells treated with $p 53$ plasmid DNA and bcl 2 AS ODN. Each value represents the mean \pm S.D. of three wells.

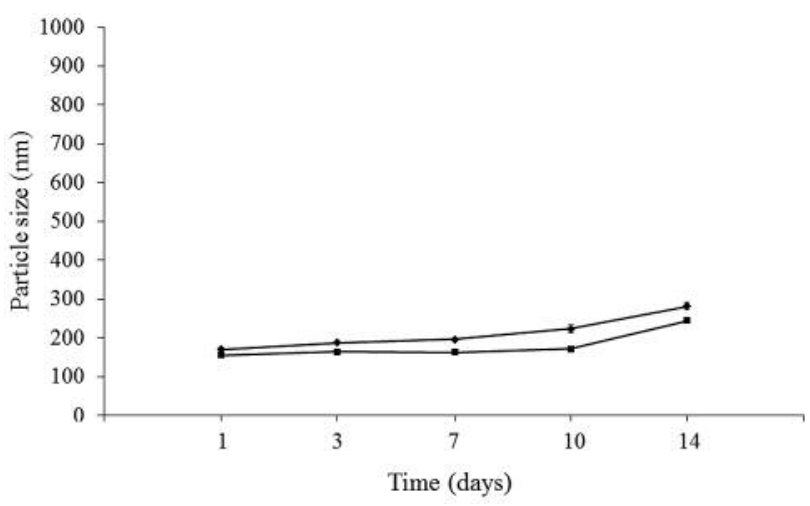

Figure 7. Particle size of PEI-CA/p53 plasmid DNA and bcl-2 AS ODN complexes at a polymer-to-NA ratio of 0.5 in 10\% BSA solution in 14 days. Polyplexes were kept at $4^{\circ} \mathrm{C}$. PEI-CA ( ) and PEI (口). Each value represents the mean $\pm S . D$. of three measurements.

Recently, conjugation of CA to PEI 25KDa has been reported to decrease cytotoxicity of PEI $(5,18)$. Deoxycholic acid-modified PEI1.8KDa had lower cytotoxicity than PEI1.8KDa in human coronary artery smooth muscle cells (4).

\section{Conclusion}

PEI-CA was able to condense plasmid DNA and AS ODN, and produce complexes less than $200 \mathrm{~nm}$ with positive charge in a single formulation. PEI-CA had a remarkably 
low toxicity and efficient transfection performance. Codelivery of PEI-CA/p53 plasmid DNA and bcl-2 AS ODN complexes synergistically inhibited human carcinoma cell growth more than either p53 plasmid DNA or bcl-2 AS ODN used alone. This study indicated that PEI-CA is a valuable carrier for plasmid DNA and AS ODN, which has potential application in cancer gene therapy.

\section{Conflicts of Interest}

The Authors report no conflicts of interest.

\section{Acknowledgements}

This work was supported by Thailand Research Fund, the Office of the Higher Education Commission, and Srinakharinwirot University under Grant MRG5680048. This study was supported by Research Promotion Fund Srinakharinwirot University.

\section{References}

1 Glover DJ, Lipps HJ and Jans DA: Towards safe, non-viral therapeutic gene expression in humans. Nat Rev Genet 6: 299310, 2005.

2 Wang W, Li W, Ou L, Flick E, Mark P, Nesselmann C, Lux CA, Gatzen HH, Kaminski A, Liebold A, Lützow K, Lendlein A, Li RK, Steinhoff G and Ma N: Polyethylenimine-mediated gene delivery into human bone marrow mesenchymal stem cells from patients. J Cell Mol Med 15: 1989-1998, 2011.

3 Kang JH, Tachibana Y, Kamata W, Mahara A, Harada-Shiba M and Yamaoka T: Liver-targeted siRNA delivery by polyethylenimine (PEI)-pullulan carrier. Bioorg Med Chem 18: 3946-3950, 2010.

4 Kim D, Lee D, Jang YL, Chae SY, Choi D, Jeong JH and Kim SH: Facial amphipathic deoxycholic acid-modified polyethyleneimine for efficient MMP-2 siRNA delivery in vascular smooth muscle cells. Eur J Pharm Biopharm 81: 14-23, 2012.

5 Dube B, Rose L, Sawant K and Uludag H: Cholic acid modified $2 \mathrm{kDa}$ polyethylenimine as efficient transfection agent. Biotechnol Prog 29: 1337-1341, 2013.

6 Jeon SY, Park JS, Yang HN, Woo DG and Park KH: Co-delivery of SOX9 genes and anti-Cbfa-1 siRNA coated onto PLGA nanoparticles for chondrogenesis of human MSCs. Biomaterials 33: 4413-4423, 2012.

7 Weecharangsan W, Opanasopit P, Yingyongnarongkul B, Kewsuwan P and Lee RJ: Co-delivery of plasmid DNA and antisense oligodeoxyribonucleotide into human carcinoma cells by cationic liposomes. Curr Pharm Biotechnol 15: 790-799, 2014.
8 Boyd SD, Tsai KY and Jacks T: An intact HDM2 RING-finger domain is required for nuclear exclusion of p53. Nat Cell Biol 2: 563-568, 2000.

9 Shim MS and Kwon YJ: Dual mode polyspermine with tunable degradability for plasmid DNA and siRNA delivery. Biomaterials 32: 4009-4020, 2011.

10 Chang Kang $\mathrm{H}$ and Bae YH: Co-delivery of small interfering RNA and plasmid DNA using a polymeric vector incorporating endosomolytic oligomeric sulfonamide. Biomaterials 32: 49144924, 2011

11 Zheng M, Zhong Y, Meng F, Peng R and Zhong Z: Lipoic acid modified low molecular weight polyethylenimine mediates nontoxic and highly potent in vitro gene transfection. Mol Pharm 8: 2434-2443, 2011.

12 Hess GT, Humphries WH. 4th, Fay NC and Payne CK: Cellular binding, motion, and internalization of synthetic gene delivery polymers. Biochim Biophys Acta 1773: 1583-1588, 2007.

13 Gautam A, Waldrep JC, Densmore CL, Koshkina N, Melton S, Roberts L, Gilbert B and Knight V: Growth inhibition of established B16-F10 lung metastases by sequential aerosol delivery of p53 gene and 9-nitrocamptothecin. Gene Ther 9: 353-357, 2002.

14 Prabha S, Sharma B and Labhasetwar V: Inhibition of tumor angiogenesis and growth by nanoparticle-mediated p53 gene therapy in mice. Cancer Gene Ther 19: 530-537, 2012.

15 Jagani H, Rao JV, Palanimuthu VR, Hariharapura RC and Gang $\mathrm{S}$ : A nanoformulation of siRNA and its role in cancer therapy: in vitro and in vivo evaluation. Cell Mol Biol Lett 18: 120-136, 2013.

16 Chen YZ, Ruan GX, Yao XL, Li LM, Hu Y, Tabata Y and Gao JQ: Co-transfection gene delivery of dendritic cells induced effective lymph node targeting and anti-tumor vaccination. Pharm Res 30: 1502-1512, 2013.

17 Weecharangsan $\mathrm{W}$ and Lee RJ: Growth inhibition and chemosensitization of human carcinoma cells by human serum albumin-coated liposomal antisense oligodeoxyribonucleotide against bcl-2. Drug Deliv 19: 292-297, 2012.

18 Weecharangsan W, Paecharoenchai O, Niyomtham N, Opanasopit P, Yingyongnarongkul B and Lee RJ: Cholic acidmodified polyethylenimine for gene delivery into human carcinoma cells. Adv Mater Res 1060: 3-6, 2015. 